\title{
Adenotonsillar Granuloma: Histopathological Correlation
}

\author{
Khalid Al-Sebeih ${ }^{a, b}$ Kenneth Katchy ${ }^{c}$ \\ ${ }^{a}$ Department of Surgery, Faculty of Medicine, Health Sciences Centre, Kuwait University, and Departments of \\ ${ }^{b}$ Otolaryngology and 'Pathology, Al-Sabah Hospital, Kuwait
}

Key Words

Tonsils · Adenoid · Granuloma, adenotonsillar

\begin{abstract}
Objectives: This study was undertaken to investigate the presence and nature of granulomatous changes in the adenotonsillar tissues and their relation to systemic disorders. Materials and Methods: The study was a retrospective clinicopathological review; 21,410 specimens of tonsil and adenoid tissue were subjected to histological examination during the period from 1995 to 2003. Twenty-three cases of tonsillar and adenoid granuloma (12 males and 11 females) were identified. Haemotoxylin and eosin stains were reviewed and clinical features noted. Results: 0 f 23 cases, 11 were adenotonsillectomies, 10 tonsillectomies, 1 adenoidectomy and 1 excision biopsy of the right tonsil. Histologically, the slides reviewed showed 4 types of granulomatous inflammation that can affect the adenotonsillar tissues. The most common type was non-caseating epithelioid granulomas. Clinically, 22 cases presented with symptoms of chronic tonsillitis, nasal obstruction and obstructive sleep apnoea. None had any systemic granulomatous disorders. Only 1 case had tuberculosis. Conclusion: In all the cases but one there was no obvious systemic aetiology for the granulomatous changes in the adenotonsillar tissues. Hence, the cost effectiveness of clinicopathological examination of the resected adenoid and tonsil is still questionable.
\end{abstract}

Copyright $\odot 2007$ S. Karger AG, Basel
(C) 2007 S. Karger AG, Basel

1011-7571/07/0166-0450\$23.50/0

Fax +41613061234 E-Mail karger@karger.ch www.karger.com

\section{Introduction}

Granulomatous inflammation of the tonsils and adenoids is rare, but when present, a systemic or local disorder has to be ruled out. Cases of tonsillar enlargement due to sarcoidosis [1-4], Crohn's disease [1], tuberculosis [5, 6], fungal infection and histoplasmosis [7] have been reported. In most of the few reports of granulomatous disease, an obvious local or systemic disorder was the cause of the granulomatous reaction in the tonsil and adenoids.

\section{Materials and Methods}

This study is a retrospective review of the registry of histopathological specimens of tonsillar and adenoidal tissues obtained between 1995 and 2003 in the Department of Pathology at Al-Sabah Hospital, Kuwait. It is limited to patients with no known systemic or local disorders at the time of tonsillectomy or adenoidectomy.

Histological findings were correlated with clinical presentation at the time of surgery and during the postoperative period. Haemotoxylin and eosin (HE) staining of paraffin sections of all tonsillar and adenoidal tissues was done. The slides were evaluated for the presence, distribution and type of granuloma. The blocks of reconfirmed granulomas were re-cut and sections stained for acid-fast bacteria (Ziehl-Neelsen method, modified by Armed Forces Institute of Pathology, USA), and fungus (Grocott's methenamine silver nitrate method) to rule out the presence of infectious organisms. Pathology results were supplemented by demographic and clinical data provided by the treating surgeon. The postoperative follow-up was noted for any clinical or laboratory evidence of specific disease. 
Fig. 1. Non-caseating granuloma is seen within a follicle. HE.

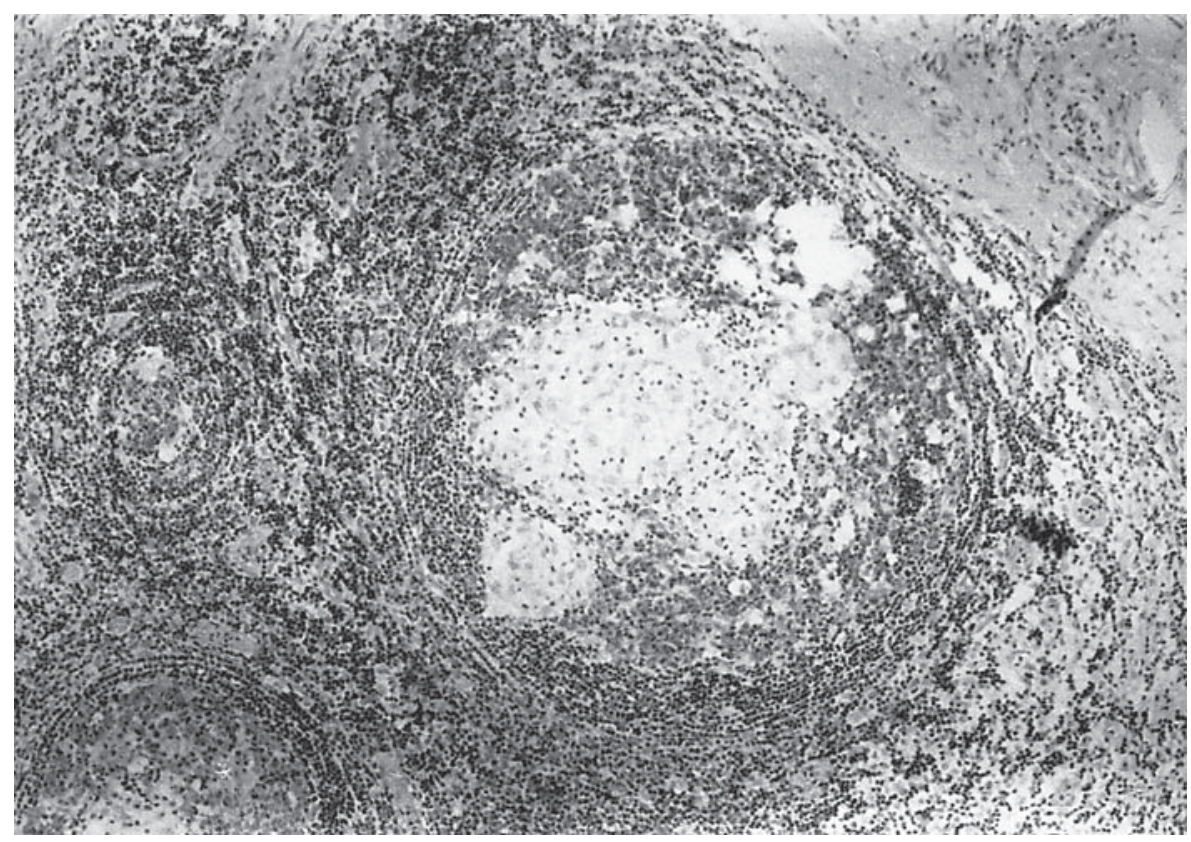

\section{Results}

Between 1995 and 2003, out of a total of 21,410 specimens, 23 cases of adenotonsillar granulomas were detected affecting 12 males (aged 3-65 years) and 11 females (3-33 years). Males were older, averaging 18 years compared to females, averaging 12.5 years, with no specific explanation for this difference. Most patients presented pre-operatively with a history of chronic or repeated attacks of tonsillitis $(\mathrm{n}=12)$, followed by nasal obstruction $(\mathrm{n}=9)$ with obstructive sleep apnoea in 7 cases; 2 patients presented with unilateral palatine tonsil hypertrophy. The pre-operative diagnostic impression of the treating physician was chronic tonsillitis in 13 cases, obstructive sleep apnoea in 7 patients, and tuberculosis or malignancy in 1 patient. Fourteen cases of the granulomatous lesions involved a palatine tonsil alone (6 bilateral, 8 unilateral); 8 cases involved adenoids and palatine tonsils, and 1 case involved an adenoid only.

Routine laboratory investigations including complete blood count were performed pre-operatively. Of interest, lymphocytosis of more than $50 \%$ of the differential white cell count was noticed in 19 patients (82.6\%). Chest Xrays were performed in all patients, with no abnormality reported. Intra-operatively, 13 patients (56.5\%) had extensive fibrosis of the tonsillar tissues with more bleeding than usual. Two patients had primary postoperative haemorrhage. The tuberculin test was done postopera- tively with only 1 positive result (65-year-old male), who presented with right unilateral tonsillar hypertrophy for which he had undergone tonsillectomy to rule out malignancy. Histopathological study confirmed the diagnosis of tuberculosis. All patients had been followed up for a period ranging from 2 to 8 years. To date, except for 1 patient with tuberculosis, none have had a specific diagnosis. Systemic disorders such as sarcoidosis, brucellosis and lymphomas have been ruled out.

\section{Pathology}

A total of 8 patients had granulomas in both tonsils and adenoids, 6 in both tonsils only, 8 in unilateral tonsils (4 in the right and 4 in the left tonsils) and 1 had granuloma in the adenoid only. The lesions were categorized according to type (morphology), distribution (discrete or coalescent) and location (follicular and parafollicular, parafollicular alone, peritonsillar). Four types of lesions were detected with 23 cases of adenotonsillar granulomas (table 1). The majority were non-caseating epithelioid granuloma $(n=20)$. Other types included caseating epithelioid ( $\mathrm{n}=1)$, foreign-body $(\mathrm{n}=1)$ and miscellaneous granuloma $(n=2)$. Non-caseating epithelioid granulomas alone were found in 20 patients and coexisted with a miscellaneous form of granuloma in 1 case. Subjectively, they varied from few to moderate, or extensive in numbers. They were discrete ( 12 cases) or coalescent ( 8 cases). The location ranged from follicular and parafollicular ar- 
Fig. 2. Miscellaneous granuloma: collection of foamy histiocytes, giant cells and small lymphocytes. A large vacuole is seen in the lower part of the granuloma. HE.

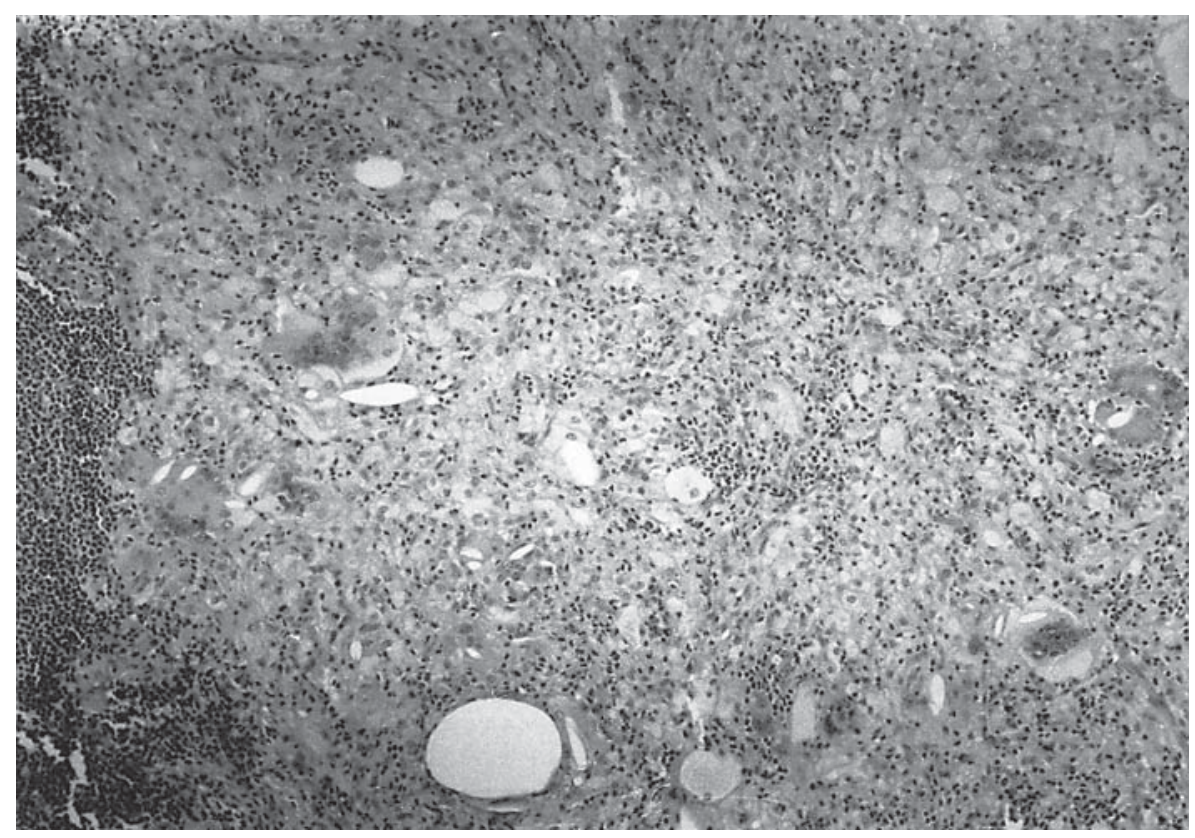

Table 1. Histopathological type of the granuloma

\begin{tabular}{lc}
\hline Type of granuloma & Cases $(\mathrm{n}=23)$ \\
\hline $\begin{array}{l}\text { Non-caseating epithelioid granuloma } \\
\text { Distribution }\end{array}$ & 20 \\
$\quad$ Discrete & 12 \\
$\quad$ Coalescent & 8 \\
Location & \\
$\quad$ Follicular & 14 \\
$\quad$ Parafollicular & 5 \\
$\quad$ Paratonsillar & 1 \\
Caseating granuloma & 1 \\
Foreign body granuloma & 1 \\
Miscellaneous granuloma & 1
\end{tabular}

eas in 14 cases (fig. 1), the parafollicular zone alone in 4 cases to the peritonsillar area in 1 case. Caseating granulomas were identified in 1 patient with right tonsillar biopsy. They were coalescent and had a central caseation. Miscellaneous granulomas were composed mostly of foamy macrophages mixed with lymphocytes, multinucleated giant cells, cholesterol crystals and occasional vacuoles (fig. 2). In 1 patient, the granuloma was solitary; in another it co-existed with multiple discrete non-caseating granulomas and was located adjacent to a ruptured crypt (table 1). The Ziehl-Neelsen stain for acid-fast bac- teria was positive in 1 patient who had a caseating epithelioid granuloma in the histopathological examination of the tonsil. Fungal stains were negative in all cases.

\section{Discussion}

Granulomatous inflammation involving the palatine tonsils occurs in numerous settings, including tuberculosis, fungal infection, Hodgkin's disease [8-10], keratinizing squamous cell carcinoma $[11,12]$ and tonsillar malakoplakia $[13,14]$. It is seen most commonly in tuberculosis and less frequently in fungal and unusual bacterial infections.

Our series showed patients with no known systemic diseases and in whom postoperative adenotonsillar tissues showed non-specific granulomatous inflammatory changes. Only 1 of the patients had had a diagnosis of tuberculosis. No other systemic disorder was noted in any of the other patients.

Primary tonsillar tuberculosis is rare and seen in countries with a high incidence of tuberculosis. Diagnosis is made by histopathological picture and culture results. The clinical picture could resemble sarcoidosis with pulmonary disease, cervical lymphadenopathy and granulomatous inflammation. This necessitates a proper diagnosis since the treatment modalities of both differ vastly. This is difficult especially if no acid-fast bacilli are 
seen. Our single adult male patient was initially diagnosed as having a non-specific granulomatous tonsillitis, with negative Ziehl-Neelsen staining of sputum and negative culture for acid-fast bacilli. However, he was clinically diagnosed after tonsillectomy and histopathological examination of the specimen. He was successfully treated with antituberculosis medications.

Routine histological examination of the tonsil and adenoid remains controversial. Missing unsuspected diagnosis such as malignancy and granulomatous disease and the medicolegal consequences are the main reasons $[15$, 16]. Although there is no consensus regarding routine microscopic examination of the tonsils and adenoids, several studies considered that the histological examination of the tonsils and adenoids results in unnecessary cost and consumption of resources and time. Nevertheless, examination should be reserved for selected cases, such as older patients and patients with gross asymmetry and a history of malignancy [15-17]. Our series demonstrates the prevalence of granulomatous afflictions of the tonsils and adenoids in otherwise healthy individuals. The fate of this non-specific granulomatous disease is unknown. Of clinical interest, 19 patients (82\%) showed lymphocytosis in the pre-operative evaluation. In addition, 2 patients (8\%) developed posttonsillectomy bleeding in which the granuloma might have played a role.

\section{Conclusion}

Since the clinical significance of granulomatous reactions is still obscure and the rate of occurrence of the idiopathic granulomatous reaction $(0.001 \%)$ is low, the validity of the histopathological examination of all surgical specimens of tonsils and adenoids remains questionable.

\section{References}

1 Kardon D, Thompson L: A clinicopathological series of 22 cases of tonsillar granulomas. Laryngoscope 2000;110:476-481.

-2 Altug H, Tahsinoglu M, Celikoglu S: A case of tonsillar localization of sarcoidosis. J Laryngol Otol 1973;87:417-421.

-3 Yarington C, Smith G, Benzmiller J: Value of histologic examination of tonsils: a report of isolated tonsillar sarcoidosis. Arch Otolaryngol 1967;85:680-681.

4 Dash GI, Kimmelman CP: Head and neck manifestation of sarcoidosis. Laryngoscope 1984;98:50-53.

5 Selimoglu M, Sutbeyaz Y, Ciftcioglu M, Parlak M, Esrefoglu M, Ozturk A: Primary tonsillar tuberculosis: a case report. J Laryngol Otol 1995; 109:880-882.

6 Anim J, Dawlatly E: Tuberculosis of the tonsil revisited. West Afr J Med 1991;10:194197.

7 Amendoeira M, Coutinho S: Isolation of Toxoplasma gondii from the saliva and tonsils of a three-year-old child. J Infect Dis 1982;145:587.
-8 Kadin M, Donaldson S, Dorfman R: Isolated granuloma in Hodgkin's disease. N Engl J Med 1970;283:859-861.

-9 O'Connell M, Schimpff S, Kirschner R, Abt A, Wiernik P: Epithelioid granuloma in Hodgkin disease: a favorable prognostic sign? JAMA 1975;233:886-889.

10 Sacks E, Donaldson S, Gordon J, Dorfman R: Epithelioid granulomas associated with Hodgkin's disease: clinical correlations in 55 previously untreated patients. Cancer 1978; 41:562-567.

-11 Segawa Y, Takigawa N, Okahara M, Maeda Y, Takata I, Fujii M, Mogami H, Mandai K, Kataoka M: Primary lung cancer associated with diffuse granulomatous lesions in the pulmonary parenchyma. Intern Med 1996; 35:728-731.

12 Safall H, Azar HA: Keratin granulomas in irradiated squamous cell carcinoma of various sites. Cancer Res 1966;26:500-508.
13 Vitellaro-Zuccarello L, Felletti V, Paizis G, Spinelli M: Ultrastructural study of granulomatuos tissues in tonsillar malakoplakia. Histol Histopathol 1987;2:307-312.

14 Abdou N, Nampombejara C, Sagama A, Regald C, Stechschulde D, Gourely W, Watanabe I, Lindsey N, Allen M: Malakoplakia: evidence for monocyte lysosomal abnormality correctable by cholinergic agonist in vitro and in vivo. N Engl J Med 1977;297:14131419.

15 Alvi A, Vartanian AJ: Microscopic examination of routine tonsillectomy specimens: is it necessary? Otolaryngol Head Neck Surg 1998;119:361-363.

16 Dohar JE. Bonilla JA: Processing of adenoid and tonsil specimens in children: a national survey of standard practices and a five-year review of the experience at the Children's Hospital of Pittsburgh. Otolaryngol Head Neck Surg 1996;115:94-97.

17 Wiebel E: Pathological findings of clinical value in tonsils and adenoids. Acta Otolaryngol (Stockh) 1965;60:331-338. 